\title{
Genetic divergence, population differentiation and phylogeography of the cicada Subpsaltria yangi based on molecular and acoustic data: an example of the early stage of speciation?
}

Yunxiang Liu' ${ }^{1}$ Christopher H. Dietrich ${ }^{2}$ and Cong Wei ${ }^{1^{*}}$

\begin{abstract}
Background: Geographical isolation combined with historical climatic fluctuations have been identified as two major factors that contribute to the formation of new species. On the other hand, biotic factors such as competition and predation are also able to drive the evolution and diversification of organisms. To determine whether geographical barriers contributed to population divergence or speciation in the rare endemic cicada Subpsaltria yangi the population differentiation, genetic structure and phylogeography of the species were investigated in the Loess Plateau and adjacent areas of northwestern China by analysing mitochondrial and nuclear DNA and comparing the calling song structure of 161 male individuals.

Results: The results reveal a low level of genetic differentiation and relatively simple phylogeographic structure for this species, but two independent clades corresponding to geographically isolated populations were recognised. Genetic and geographical distances were significantly correlated among lineages. Results of divergence-time estimation are consistent with a scenario of isolation due to glacial refugia and interglacial climate oscillation in northwestern China. Significant genetic divergence was found between the population occurring in the Helan Mountains and other populations, and recent population expansion has occurred in the Helan Mountains and/or adjacent areas. This population is also significantly different in calling song structure from other populations.

Conclusions: Geographical barriers (i.e., the deserts and semi-deserts surrounding the Helan Mountains), possibly coupled with related ecological differences, may have driven population divergence and allopatric speciation. This provides a possible example of incipient speciation in Cicadidae, improves understanding of population differentiation, acoustic signal diversification and phylogeographic relationships of this rare cicada species of conservation concern, and informs future studies on population differentiation, speciation and phylogeography of other insects with a high degree of endemism in the Helan Mountains and adjacent areas.
\end{abstract}

Keywords: Acoustic signals, Allopatric speciation, Cicadidae, Geographical isolation, Northern China, Population differentiation

\footnotetext{
* Correspondence: congwei@nwsuaf.edu.cn

${ }^{1}$ State Key Laboratory of Crop Stress Biology for Arid Areas, and Key

Laboratory of Plant Protection Resources and Pest Management, Ministry of

Education, College of Plant Protection, Northwest A\&F University, Yangling

712100, Shaanxi, China

Full list of author information is available at the end of the article
}

(c) The Author(s). 2019 Open Access This article is distributed under the terms of the Creative Commons Attribution 4.0 International License (http://creativecommons.org/licenses/by/4.0/), which permits unrestricted use, distribution, and reproduction in any medium, provided you give appropriate credit to the original author(s) and the source, provide a link to the Creative Commons license, and indicate if changes were made. The Creative Commons Public Domain Dedication waiver (http://creativecommons.org/publicdomain/zero/1.0/) applies to the data made available in this article, unless otherwise stated. 


\section{Background}

Geographic isolation is essential to most speciation events, because biogeographic barriers (due to distance, water bodies, mountains, deserts, etc.) separate populations, impede gene flow, and drive genetic differentiation, which may lead to allopatric speciation [1-3]. The mosaic of high mountains in East Asia forms a complex terrain imposing geographical barriers hindering movement of many animal species $[1,4]$. The uplift of the Qinghai-Tibet Plateau (about 1.7-3.6 million years ago (Ma)), in particular, had a profound impact on the surrounding geography and environment, generating sources and reservoirs of genetic and species diversity $[5,6]$. Previous studies of East Asian insects confirmed that the complex local topography and geographic isolation had a marked effect on the distribution and demography of many insects, e.g., Bactrocera cucurbitae (Diptera: Tephritidae) [7], Apocheima cinerarius (Lepidoptera: Geometridae) [8], Panesthia cockroaches (Blattaria: Blaberidae) [9], and Halyomorpha halys (Hemiptera: Pentatomidae) [10]. During the past three million years, global climate has fluctuated greatly, which resulted in the recent major ice age [11], and substantial changes in the distributions of many living organisms, expressed differently in temperate and tropical zones [12, 13]. During the ice age, mountainous areas are thought to have harboured many refugial populations, which led to the formation of new lineages/taxa and contributed to higher genetic diversity $[14,15]$. Such changes include fragmentation of previously contiguous populations which, in animals, may result in both genetic and behavioral divergence. In particular, acoustic signals function in species recognition and mate choice in a wide range of taxa. It has been proposed that divergence in acoustic signals often plays an important part in speciation, and study of such signals has been used to discover examples of incipient or cryptic speciation $[16,17]$.

The increasing desertification of northern China caused by the uplift of the QTP effectively changed the biodiversity of this area $[18,19]$. The Helan (HL) Mountains and adjacent areas of northern China, which were first formed during the Mesozoic between 205 and $135 \mathrm{Ma}$ and reach a maximum elevation of $3556 \mathrm{~m}$, may be an ideal location to investigate the effects of geographical isolation on speciation [20, 21]. These mountains are considered an important area for biodiversity conservation in China because they provide suitable habitats and environmental conditions for many highly endemic species [22, 23]. The mountains are surrounded by deserts and semi-deserts which may serve as geographical barriers to species with limited dispersal ability [24], and the isolated peaks may be equivalent to islands biogeographically $[25,26]$. The patchwork of mountains, deserts and semi-deserts in this region may promote the differentiation of populations and increase the likelihood of speciation.
The large body size and low dispersal ability of cicadas has led to their being used as model organisms for phylogeographic and speciation studies in different regions of the world including New Zealand [27, 28], South Africa [29], North America [30] and the Mediterranean area [31]. The cicada Subpsaltria yangi Chen is the only known species of the tribe Tibicininii in China. The species was previously placed in the subfamily Tettigadinae [32, 33] but was removed recently to the subfamily Tibicininae [34]. This rare endemic species distributed in the Loess Plateau and adjacent areas of northwestern China [35] is unusual in that the males possess a well-developed stridulatory mechanism in addition to the timbals, and in that the females also possess the same stridulatory organs as males [32, 33]. The species was, until recently, considered to be extinct, because it had not been found in the field since 1980s and was only known from museum specimens collected from the center of Shaanxi Province. Nevertheless, S. yangi was rediscovered in June of 2011 during a survey of the insect fauna of the Helan Mountains which is surrounded by deserts and semi-desert. This provided an opportunity to study this little-known species, and led to the discovery of the positive phonotaxis and acoustical sexual mimicry in males [35-37]. During our field investigations of $S$. yangi since 2011, a few more populations were discovered from the Loess Plateau in Shaanxi, Shanxi and Gansu provinces, which were all attracted and sampled using our special acoustic playback method [35]. Interestingly, the habitats inhabited by the species in the Helan Mountains and the Loess Plateau are greatly divergent. Populations of $S$. yangi occurring in the Helan Mountains mainly feeds on Ephedra lepidosperma C.Y. Cheng (Ephedraceae), a shrub endemic to the Helan Mountains, but populations distributed in the Loess Plateau mainly feed on Ziziphus jujuba Mill. var. spinosa (Bunge) $\mathrm{Hu}$ ex H. F. Chow (Rhamnaceae) [35-37]. The differences in habitats and diets suggest that niche expansion and significant genetic divergence may have occurred among populations of this cicada species.

To determine whether geographical barriers are important factors driving population divergence or allopatric speciation of $S$. yangi, we explored the pattern of genetic divergence among populations of this species using phylogeographic analyses based on mitochondrial and nuclear gene sequences. The genetic distance and divergence times were estimated to assess the potential influence of historical climatic fluctuations on population differentiation and niche expansion. The calling song structures of males of four representative populations were also investigated and compared to further clarify the extent of population differentiation or speciation. 


\section{Materials and methods}

\section{Species and sampling}

Samples were collected throughout the formerly documented range and potential range of $S$. yangi, including Shaanxi Province, Shanxi Province, Gansu Province, and Ningxia Hui Autonomous Region. In total, 161 specimens, representing ten natural populations, were collected from 2013 to 2017. Sweep netting and acoustical trap sampling were used to collected individuals from different drought-tolerant dwarf shrubs or herbaceous plants, which generally do not exceed $1 \mathrm{~m}$ in height in the dry habitats sampled. Sampling site and sample-size information are summarized in Table 1 and depicted in Fig. 1. Tissue samples were frozen in individually labeled containers in $100 \% \mathrm{EtOH}$. All vouchers are deposited in the Entomological Museum of Northwest A\&F University (NWAFU), Yangling, China.

\section{DNA extraction, amplification and sequencing}

A Biospin Insect Genomic DNA Extraction Kit (Bioer Technology Co., Ltd., Hangzhou, China) was used to extract total genomic DNA from leg muscle following the manufacturer's instructions. Standard polymerase chain reaction (PCR) methods were used to amplify partial sequences of four mtDNA regions (cytochrome c oxidase subunit I (COI), cytochrome c oxidase subunit II (COII), cytochrome b $(C y t b)$, and ATPase subunits $(A 6 A 8))$ and two nuclear gene segments (internal transcribed spacer 1 (ITS1) and the elongation factor-1 alpha gene $(E F-1 \alpha)$ ) from representative samples. The primer pairs used in this study for these six genes are presented in Additional file 1: Table S1. PCR programs were conducted in a total volume of $25 \mu \mathrm{l}$ using the following thermal cycling conditions: an initial denaturation at $95^{\circ} \mathrm{C}$ for 3 min, followed by 30 cycles of $95^{\circ} \mathrm{C}$ for $30 \mathrm{~s}, 44.9-59.3^{\circ} \mathrm{C}$ for $45 \mathrm{~s}\left(51.4{ }^{\circ} \mathrm{C}\right.$ for $\mathrm{COI}, 44.9^{\circ} \mathrm{C}$ for $\mathrm{COII}, 54.4{ }^{\circ} \mathrm{C}$ for Cytb, $47.7^{\circ} \mathrm{C}$ for $A 6 A 8,59.3^{\circ} \mathrm{C}$ for ITS1 and $54.4{ }^{\circ} \mathrm{C}$ for $E F-1 \alpha$ ), and an extension at $72^{\circ} \mathrm{C}$ for $60 \mathrm{~s}$, and a final extension step of $72{ }^{\circ} \mathrm{C}$ for $7 \mathrm{~min}$. PCR products were visualized on a $1 \%$ agarose gel with ethidium bromide staining. PCR products were then purified and sequenced in both directions by Shanghai Sangon Biological Engineering Technology and Service Co., Ltd. All sequences gathered in this study have been deposited in GenBank (Accession Nos.: COI: MG279557-MG279685; COII: MG592751-MG592882; Cytb: MG387233-MG387361; A6A8: MG281557-MG281685; ITS1: MG592883MG593021; EF-1 $\alpha$ : MG387362-MG387402).

\section{Phylogenetic analysis}

The chromatograms of each sequence were proofread and then assembled using SEQMAN PRO (DNAstar, Madison). Each protein-coding sequence was translated for confirmation and assignment of codon positions using PREMIER v5.0 (Premier Biosoft International, Palo Alto, CA). Multiple sequence alignment was carried out in CLUSTAL X v1.81 [38], with gappy columns at the beginning and end of the alignment manually deleted with BIOEDIT v7.0.9.0 [39]. To confirm the alignment, PRIMER PREMIER v5 [40] was used to translate the sequences into amino acids. The alignment applied for phylogenetic analyses was measured for its sensitivity to misaligned regions identified with the program GBLOCKS [41], as no repeatable criteria in the manual alignment could be used to determine which regions were divergent or ambiguously aligned by BIOEDIT. DAMBE v5.3.74 [42] was conducted to test the level of substitution saturation of each gene and each codon position of each protein-coding gene. No insertions, deletions, or stop codons were present in the alignment. Base frequency and the number of variable and parsimony informative sites were calculated in MEGA v6 [43]. We tested for homogeneity of base frequencies across taxa for each gene using the chi-square test implemented in PAUP* v4.0b10 [44]. Mean sequence divergences among the major clades were calculated using MEGA v6 under the pairwise Kimura two-parameter (K2P) model.

Table 1 Occurrence data for the 10 populations of S. yangi used for molecular analyses in this study

\begin{tabular}{|c|c|c|c|c|c|}
\hline Population & Collection location & Longitude (E) & Latitude (N) & Collection date & Number of individuals \\
\hline FX & Fengxiang, Shaanxi & $107^{\circ} 23^{\prime} 20^{\prime \prime}$ & $34^{\circ} 31^{\prime} 56^{\prime \prime}$ & $15 / 6 / 2016$ & 20 \\
\hline $\mathrm{HC}$ & Hancheng, Shaanxi & $109^{\circ} 35^{\prime} 54^{\prime \prime}$ & $34^{\circ} 54^{\prime} 35^{\prime \prime}$ & $25 / 5 / 2014$ & 18 \\
\hline $\mathrm{HL}$ & Helan Mountains, Ningxia & $106^{\circ} 51^{\prime} 20^{\prime \prime}$ & $38^{\circ} 57^{\prime} 47^{\prime \prime}$ & $5 / 6 / 2015$ & 20 \\
\hline LF & Linfen, Shanxi & $111^{\circ} 03^{\prime} 40^{\prime \prime}$ & $36^{\circ} 04^{\prime} 37^{\prime \prime}$ & $3 / 6 / 2015$ & 20 \\
\hline LL & Luliang, Shanxi & $111^{\circ} 34^{\prime} 50^{\prime \prime}$ & $37^{\circ} 39^{\prime} 54^{\prime \prime}$ & $7 / 6 / 2015$ & 18 \\
\hline$P L$ & Pingliang, Gansu & $106^{\circ} 39^{\prime} 54^{\prime \prime}$ & $35^{\circ} 51^{\prime} 00^{\prime \prime}$ & 20/6/2016 & 17 \\
\hline TB & Taibai, Shaanxi & $107^{\circ} 31^{\prime} 22^{\prime \prime}$ & $34^{\circ} 02^{\prime} 46^{\prime \prime}$ & $14 / 6 / 2017$ & 2 \\
\hline TC & Tongchuan, Shaanxi & $108^{\circ} 34^{\prime} 56^{\prime \prime}$ & $34^{\circ} 50^{\prime} 36^{\prime \prime}$ & $14 / 6 / 2014$ & 18 \\
\hline YA & Yan'an, Shaanxi & $109^{\circ} 28^{\prime} 33^{\prime \prime}$ & $36^{\circ} 50^{\prime} 50^{\prime \prime}$ & $29 / 5 / 2014$ & 20 \\
\hline YH & Yonghe, Shanxi & $111^{\circ} 05^{\prime} 20^{\prime \prime}$ & $36^{\circ} 58^{\prime} 48^{\prime \prime}$ & $6 / 6 / 2015$ & 10 \\
\hline
\end{tabular}




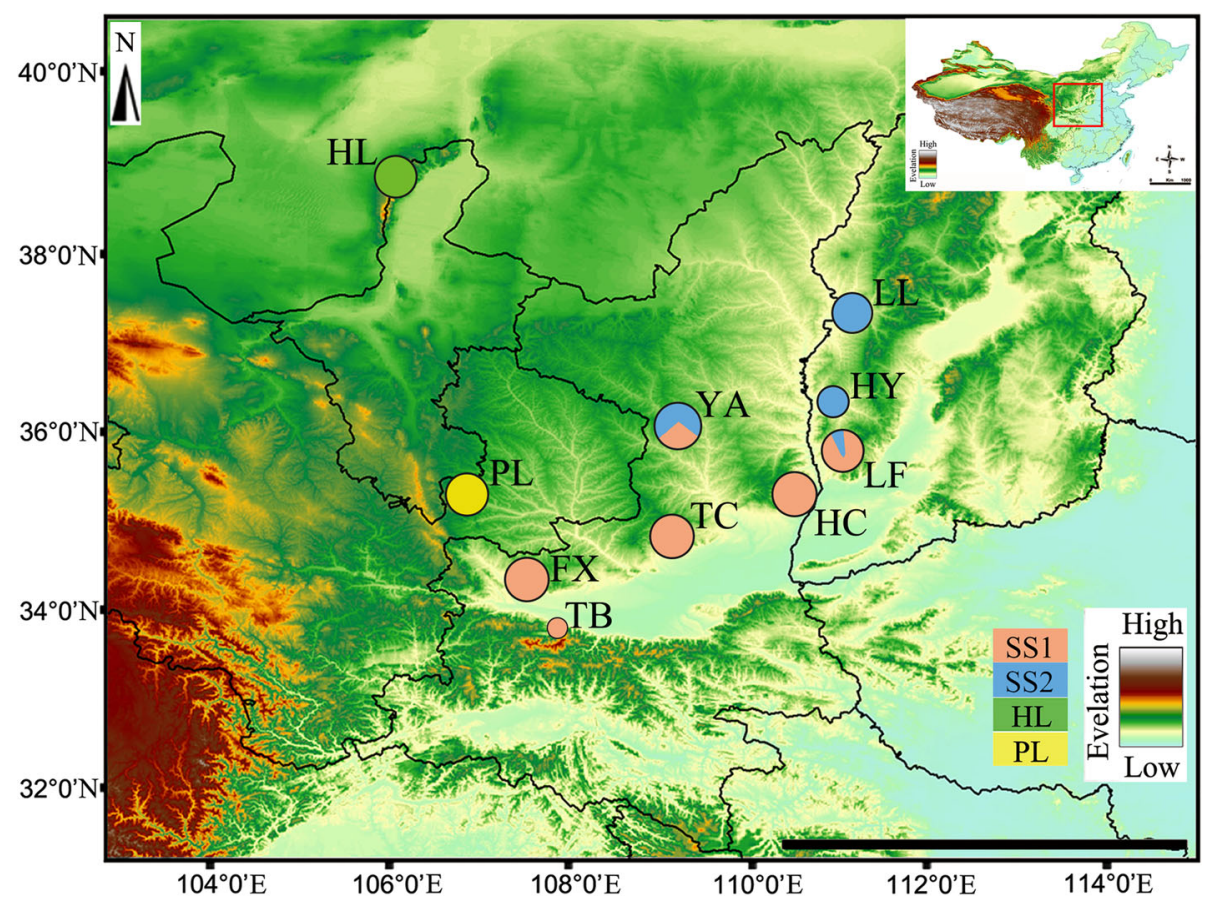

Fig. 1 The geographic distribution of S. yangi species sampled in this study. Detailed information on the locations population codes are presented in Table 1. Pie charts for each population correspond to the proportion of each genetic cluster in the population. Figure generated in ArcGIS 10 (Environmental Systems Research Institute). Size of circles indicate sample size. SS: Group in Shaanxi and Shanxi province. HL: Population in Ningxia Hui Nationality Autonomous Region. PL: Population in Gansu province

The program PARTITIONFINDER v1.1.1 [45] was used to estimate evolutionary models and the most suitable partitioning strategies for each partition, with different potential groups of 1 st, 2nd and 3rd codon positions of protein-coding genes given to the program. Sequence models and alternative partitioning were compared using the Bayesian Information Criterion (BIC). Bayesian analysis (BI) was conducted using MrBayes v3.1.2 [46]. Maximum likelihood (ML) analysis was tested using the program raxmlGUI v1.3, a graphical front-end for RAxML [47]. Under the GTR + I + G model we ran ten times for all maximum likelihood analyses with the "thorough" bootstrap setting, starting from random seeds. This was repeated until the likelihood score and parameter estimates no longer changed. In order to keep the best tree only, trees were initially evaluated under maximum parsimony by stepwise random addition with tree bisection-reconnection (TBR) branch swapping on ten replicates. Bootstraps [48] were conducted for the ML analyses using the final parameter settings for 100 pseudo replicates, saving the best tree from ten search replicates per bootstrap replicate. The bootstrap support value (BS) was estimated by analysis with 1000 replicates. We initially analysed the entire dataset $(C O I+$ $C O I I+C y t b+A 6 A 8+E F-1 \alpha+I T S 1)$, and performed subsequent analyses on the $(C O I+C O I I+C y t b+A 6 A 8)$ and $(E F-1 \alpha+I T S 1)$ datasets, respectively. Sequences from two closely related species, Okanagana utahensis and $O$. canadensis, obtained from Sueur et al. [49], were used as outgroup taxa for the phylogenetic analysis.

BI analysis was conducted using MrBayes v3.1.2. The Markov chain Monte Carlo (MCMC) algorithm was run for 2,000,000 generations, with four incrementally heated chains. The analysis involved starting from a random tree and sampling every 100 generations. The average standard deviation of split frequency among runs was lower than 0.01 , indicating that the sampling of posterior distribution was adequate. Convergence was examined using Potential Scale Reduction Factor (PSRF) and the average standard deviation of split frequencies. Stationarity was determined using TRACER v1.5 [50] by plotting the log-likelihood values versus generation number. A50\% majority-rule consensus tree with the posterior probability values was constructed by summarizing the remaining trees, before discarding the first 25\% of the yielded trees as burn-in.

\section{Population structure and history demography analysis}

The numbers of haplotypes $(\mathrm{H})$, the values of haplotype diversity (h) and nucleotide diversity ( $\pi$ ) [51] for every sampling site, lineage and population were estimated by DNASP v5.0 [51]. The neighbor-net algorithm with SPLITSTREE v4.6 [52], and a median-joining method performed with default settings in NETWORK v5.0 [53] 
were used to construct unrooted networks in order to explore the relationships among unique haplotypes. Populations were divided into haplogroups according to preceding analysis. A three-level hierarchical analysis of molecular variance (AMOVA) [54] was performed with genetic variation and fixation indices implemented in ARLEQUIN v3.5 [55] by computing conventional F-statistics from haplotypes with 1000 permutations. To explore the historical population demographics and examine whether the sequences conformed to the expectations of neutrality, Tajima's D and Fu's F statistic were computed, and 10,000 coalescent simulations were performed for each statistic to create $95 \%$ confidence intervals.

The model-based Bayesian Analysis of Population Structure (BAPS) v6.0 was used to study the genetic structure of $S$. yangi [56]. The genetic clusters probabilities (from $\mathrm{K}=1$ to $\mathrm{K}=20$ ) were surveyed with $\mathrm{COI}$ gene under "mixture analysis" and "spatial clustering of individuals" models [57]. In addition, BAPS selected 10 as the number of interactions used to assess the admixture coefficients for the reference individuals, 200 as the number of reference individuals from each genotype and 1000 as the number of interactions to assess the admixture coefficients for the genotypes.

Pairwise mismatch distribution analyses were carried on to detect evidence of past demographic expansions by DNASP v5.0. Multiple methods were performed to understand the population genetic structure of S. yangi. Pairwise Fst [58] was examined using ARLEQUIN v3.5 [55] for each pair of the sampled populations; then, Mantel tests of the genetic distance [Fst/(1-Fst)] vs the geographical distance $(\mathrm{ln} \mathrm{km})$ based on mitochondrial genes $(\mathrm{COI}+$ $C O I+C y t b+A 6 A 8)$ calculated with $\mathrm{ZT}$ v1.1 [59] were used to estimate the degree of isolation by distance.

\section{Divergence time estimation}

The divergence times for the haplotype lineages were estimated using BEAST v1.8.1 [60] based on the combined mitochondrial genes data. The data were divided into two partitions, one composed of the protein-coding genes with substitution model $\mathrm{HKY}+\mathrm{I}+\mathrm{G}$ and the other containing the ribosomal RNA gene with HKY + G. Coalescent tree priors were set to the constant size model. Because no fossils are known for this lineage, it was not possible to calibrate the molecular clock using fossil-based minimum ages $[29,61,62]$. Thus, approximate divergence times were estimated using two previously proposed conventional mutation rates for the insect mitochondrial COI gene $2.3 \%$ (i.e., 0.0115 substitutions/site per lineage) and $3.54 \%$ (i.e., 0.0177 substitutions/site per lineage) per million years [63, 64]. Two runs were executed for 200 million generations, sampling every 20,000 generations and discarding the initial $25 \%$ as burn-in. Both the posterior distribution and the effective sample sizes (ESSs) from the MCMC output were measured by TRACER v1.5 [50]. TREEANNOTATOR v1.8.0 [60] was applied to obtaining a maximum credibility tree with the $95 \%$ highest posterior density (HPD) intervals and the annotation of mean node ages. After the analyses, all parameters were assessed to determine whether a sample size $>200$ was obtained. The tree diagram with divergence time estimates was generated using FIGTREE v1.3.1 [65].

\section{Calling song structure comparison among populations}

We obtained 23 acoustic samples of the male calling song in the field on 06 June, 2017 at the Chunshugou Valley in the Helan (HL) Mountains, Ningxia Hui Nationality Autonomous Region; 21 on 01 June, 2014 at Hancheng (HC), Shaanxi Province; 19 on 05 June, 2014 at Tongchuan (TC), Shaanxi Province; and 15 on 19 June, 2016 at Pingliang (PL), Gansu Province, China, at an average temperature $\sim 30^{\circ} \mathrm{C}$. We used a linear PCM recorder (PCM-D100, Sony, China, frequency range of $20-20,000 \mathrm{~Hz}$ ) for all acoustic recordings using two stereo microphones. The original stereo format (WAV) was converted to mono at a sampling rate of $44.1 \mathrm{kHz}$ with 16 bits resolution. The analysis of acoustic properties was conducted using RAVEN PRO v1.4 (The Cornell Lab of Ornithology, Ithaca, NY, USA) and SEEWAVE v2.0.4 [66] which is a custom-made library of the R software platform [67]. Terminology adopted to describe the acoustic signals follows Puissant \& Sueur [68].

Previous study has indicated that S. yangi males produce both timbal and stridulatory sounds for intraspecific communication [36]. Therefore, the frequency domain and duration of both timbal and stridulatory sounds of the four sampled populations were compared. Fast Fourier Transform (FFT) was applied to measuring dominant frequencies with $44.1 \mathrm{~Hz}$ precision. The one-way analysis of variance (ANOVA) was used to examine the dominant frequency and duration of different parts of the calling song among different populations, followed by the Student-Newman-Keuls test. Statistical analysis was undertaken with IBM SPSS Statistics v20.0 (IBM Corp, Armonk, NY). All statistical tests were two tailed, and $P<0.05$ was considered significant.

\section{Results \\ Sequence characterization}

In total, 790 sequences of the six genes were obtained. The final alignment included $561 \mathrm{bp}$ of COI, $699 \mathrm{bp}$ of COII, 561 bp of Cytb, 657 bp of A6A8, 727 bp of ITS1, and $711 \mathrm{bp}$ of $E F-1 \alpha$. The Chi-square test revealed no significant base composition heterogeneity among the populations for any gene fragment $(P>0.05)$. COII is the most variable gene, and most of the substitutions occurred in the third codon positions of this gene. The 
ITS1 gene is more conserved than the mitochondrial genes. Within S. yangi, $5.46 \%$ of the sites in COII were parsimony-informative, compared to $0.18 \%$ in $E F-1 \alpha$.

\section{Phylogenetic relationships and population structure}

ML and Bayesian phylogenies obtained from analysis of combined mtDNA (Fig. 2a) and nuDNA (Additional file 2: Figure S1) datasets were congruent (Additional file 3: Figure S2). Twenty-two haplotypes based on combined genes (mtDNA and nuDNA) were identified (Additional file 1: Table S2). HKY + G, HKY + G + I and $\mathrm{GTR}+\mathrm{I}$ were the best-fit models for the partitions (COI $+\mathrm{COII}+C y t b+A 6 A 8),(E F-1 \alpha+I T S 1)$ and $(\mathrm{COI}+\mathrm{COII}$ $+C y t b+A 6 A 8+E F-1 \alpha+I T S 1), \quad$ respectively. Both the phylogenetic trees and the network reveal low levels of genetic differentiation and a relatively simple phylogeographic structure for this species (Fig. 2). However, the analyses recovered two independent clades corresponding to the HL population and the PL population base on the combined mtDNA (Fig. 2a). Haplotype networks for mtDNA (Fig. 2b) and nuDNA (Fig. 2c) both show that groups SS1 and SS2 formed intermediate lineages between the more divergent and independent $\mathrm{HL}$ and PL lineages. The separate HL and PL clades were supported by Bayesian PP of 0.84 and 0.86 , respectively, and ML bootstrap of 86 and $88 \%$, respectively (Fig. 2a). In contrast, no distinct differentiation was found among the remaining populations distributed in the Loess Plateau and adjacent areas (i.e., in Shaanxi and Shanxi provinces), which formed two interlaced groups, viz SS1 and SS2 (Figs. 2a and 3a). Populations distributed in Shaanxi and Shanxi showed genetic affinity, but no clear association between the clades and geographic distribution was found. SS1 and SS2 included aggregations of individuals distributed in different localities and showed no clear biogeographic structural patterns.

AMOVA of S. yangi populations indicates that mitochondrial genetic variation among the 4 groups (HL, PL, SS1, SS2) was $89.04 \%(\mathrm{Fct}=0.00974, P<0.0015)$, but only 6.42\% (Fsc $=0.00774, P<0.0015)$ among populations within groups, and $4.54 \%(\mathrm{Fst}=0.00044, P<0.0015)$ within populations (Table 2). In contrast, AMOVA of the nuclear gene ITS1 indicates that $79.33 \%$ (Fct $=$ $0.20755, P<0.0015)$ of genetic variation occurs within populations, but only $8.11 \%$ (Fst $=0.08049, P<0.0015$ ) among groups (Table 2). Based on the combined nuclear genes $(E F-1 \alpha+I T S 1)$, AMOVA indicates $85.46 \%$ $(F c t=0.17504, P<0.0015)$ of genetic variation occurs within populations (Table 2).

The median-joining network of COI haplotypes also revealed four groups, viz., HL, PL, SS1 and SS2 (Fig. 3a). AMOVA of $S$. yangi populations indicates that mitochondrial genetic variation among the 4 groups is 84.17\% (Fct $=0.84075, P<0.0015)$. Similarly, the BAPS clustering analysis for the $\mathrm{COI}$ gene supported four main groups within the ten populations $(\mathrm{K}=4$; group 1: $\mathrm{HL}$; group 2: PL; group 3: SS1 (FX, HC, LF, TB, TC, YA); group 4: SS2 (HY, LF, LL, YA); Additional file 1: Table S3; Fig. 3b). BAPS analysis for the gene ITS1 revealed two groups ( $\mathrm{K}=2$; Additional file 1: Table S3; Fig. 3b). A visual assessment of the BAPS results shows that the HL population forms a single distinct cluster, while the remaining populations form another with apparent admixture (Fig. 3b).

\section{Demographic analysis}

Mitochondrial genetic diversity indices for each population are presented in Table 3. Haplotype diversity is relatively low, ranging from 0.968 (LF) to 0.216 (TC), and nucleotide diversity ranges from 0.00191 (LF) to 0.00009 (TC). Neutrality tests conducted for the 10 populations of $S$. yangi for the combined mtDNA dataset (Table 3) indicate that the HL population shows significant negative values for both Fu's F $(p<0.05)$ and Tajima's D $(p<0.05)$ statistics. These results significantly reject the hypothesis of neutral evolution in this population, indicating that recent population expansion has occurred in the Helan Mountains and/or adjacent areas. The unimodal curve of the mismatch distribution supports the same inference of a population expansion (Additional file 4: Figure S3).

The mean Fst ranged from 0.0018 (LL population) to 0.0735 (HL population) (Table 4). Significantly, genetic divergence was found between the HL population and all other populations with the maximum mean differentiation value (mean Fst $1 / 4$ 0.0646, 0.0601-0.0735). Similarly, significant genetic differentiation was also found between the PL population and other populations (mean Fst $1 / 4$ 0.0541, 0.04080.0601 ). The Mantel test yielded an $\mathrm{r}$ value of 0.0289 for combined mitochondrial gene data $(P=0.0012)$ (Additional file 5: Figure S4), indicating a significant correlation between genetic and geographic distances in S. yangi populations.

\section{Genetic distances}

Pairwise corrected genetic distances for mitochondria DNA of $S$. yangi and outgroup species are shown in Additional file 1: Table S4. Intraspecific genetic distances of $S$. yangi (0.001-0.018) are distinctly lower than distances between $S$. yangi and the outgroup species (0.108-0.148), without overlap. Except for comparisons between the HL population and other populations, most pairwise comparisons show very low genetic distance values, suggesting these populations have a low level of genetic diversity (Additional file 1: Table S4). The highest intraspecific divergence values (0.006-0.018) are those between the HL population and the remaining 


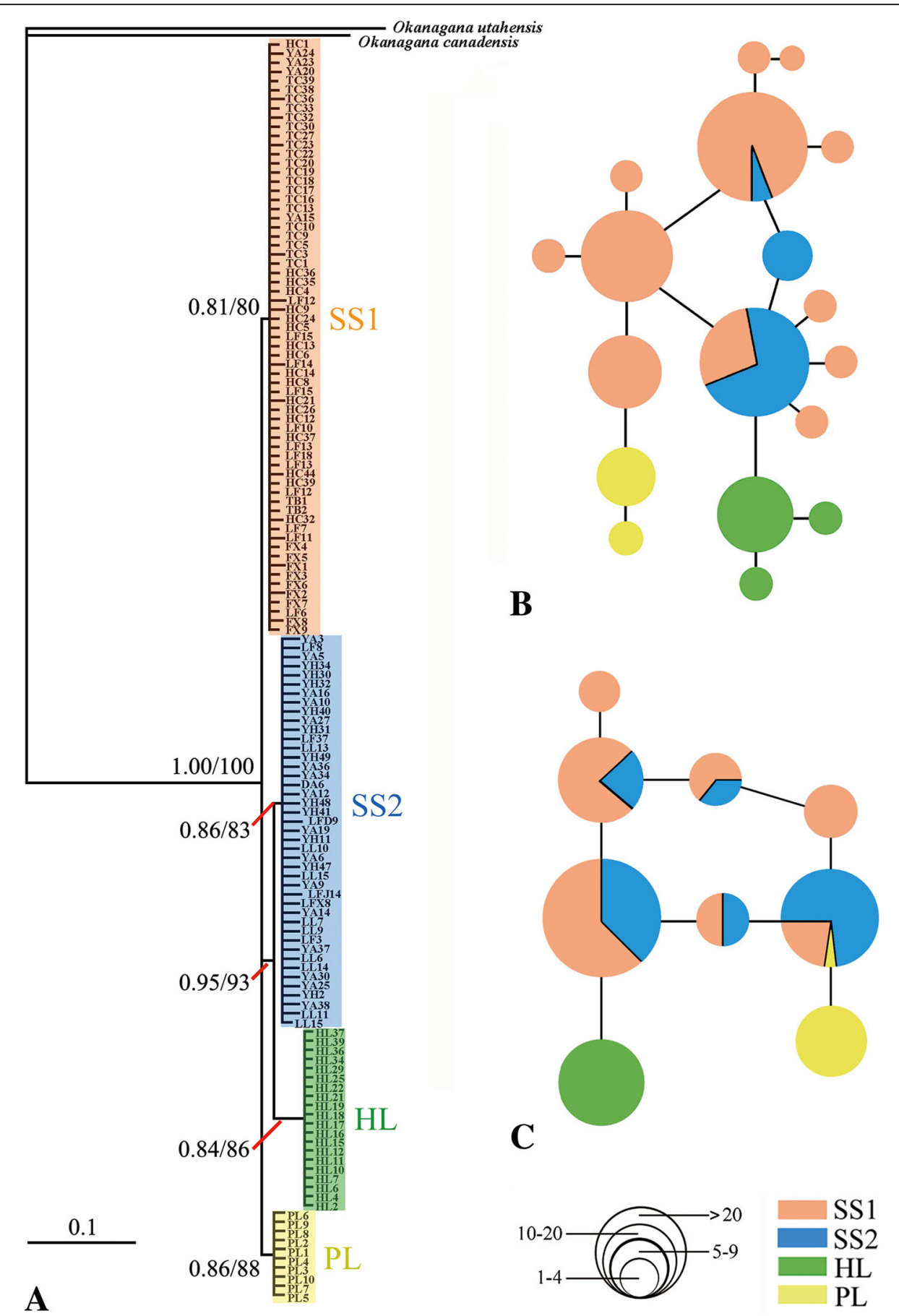

Fig. 2 Phylogenetic tree and network profile. a phylogram reconstructed based combined mitochondrial $(\mathrm{CO}+\mathrm{CO} / \mathrm{C}+\mathrm{Cytb}+\mathrm{A} 6 \mathrm{A8}) \mathrm{genes}$. Bayesian posterior probabilities/ ML bootstrap values are indicated near branches. b network of mitochondrial gene haplotypes of $S$. yangi. $\mathbf{c}$ network of nuclear gene haplotypes of $\mathrm{S}$. yangi. The sizes of circles are proportional to haplotype frequency. Colours denote lineage membership and are the same as in $\mathbf{a}$

populations. The intraspecific divergence values between the PL population (the other independent lineage) and the remaining populations, except for the HL population, increase along with the increase in geographic distance, varying from 0.005 to 0.009 .

\section{Estimation of divergence time}

The divergence-time chronogram places the split between Okanagana utahensis and the remaining species at a mean age of $\sim 3.93 \mathrm{Ma}$ (95\% highest posterior density interval, HPDI, 3.05-4.81 Ma), when the conventional 


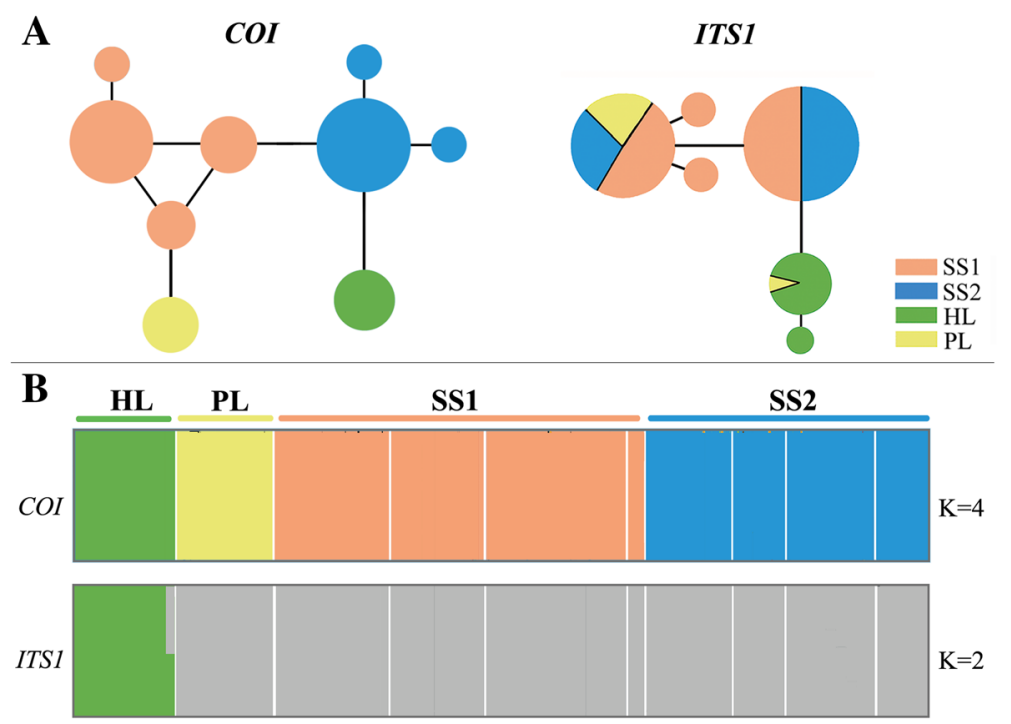

Fig. 3 Population structure of S. yangi using the Network and Bayesian analysis of population structure (BAPS). a network of S. yangi based on COI and ITSI gene haplotypes. b Bayesian analysis of population genetic structure (BAPS) based on COI $(K=4)$ and ITSI ( $K=2)$ sequences. Structure plots depicting population structure among samples from ten sites. Colours indicate different genetic clusters

insect mtDNA divergence rate of $3.54 \%$ per million years is used (Fig. 4). The estimated divergence time between $S$. yangi and Okanagana canadensis was $2.91 \mathrm{Ma}(95 \%$ HPDI, 2.21-3.61 Ma) (Fig. 4). Estimated times of divergence were $\sim 0.59 \mathrm{Ma}(95 \% \mathrm{HPDI}, 0.82-0.36 \mathrm{Ma})$ between populations $(\mathrm{HL}+\mathrm{SS} 2)$ and $(\mathrm{PL}+\mathrm{SS} 1)$. HL and SS2 diverged at $\sim 0.46 \mathrm{Ma}(95 \% \mathrm{HPDI}, 0.23-0.69 \mathrm{Ma})$, and a divergence time of $0.43 \mathrm{Ma}$ (95\% HPDI, $0.29-0.43 \mathrm{Ma}$ ) was estimated for the split of PL and SS1 (Fig. 4). When the alternative conventional mtDNA divergence rate of $2.3 \%$ per million years was used to construct the chronogram (Additional file 6: Figure S5), the estimated times of divergence were $\sim 0.29 \mathrm{Ma}$ (95\% HPDI, 0.19-0.39 Ma) between populations (HL + SS2) and (PL + SS1); HL and SS2 diverged at $\sim 0.20 \mathrm{Ma}(95 \% \mathrm{HPDI}, 0.13-0.27 \mathrm{Ma}$ ); and a divergence time of $0.19 \mathrm{Ma}$ (95\% $\mathrm{HPDI}, 0.12-0.26 \mathrm{Ma}$ ) was estimated for the split of PL and SS1 (Additional file 6: Figure S5).

Table 2 Analysis of molecular variance (AMOVA) results based on the mitochondrial genes and nuclear genes

\begin{tabular}{|c|c|c|c|c|c|}
\hline Genes & Source of variation & Fixation indices & $P$-value & Variance components & Percentage of variation \\
\hline \multirow{4}{*}{$\begin{array}{l}\mathrm{COI}+\mathrm{COII+} \\
\mathrm{Cytb}+\mathrm{A} 6 \mathrm{~A} 8\end{array}$} & Among groups & $\mathrm{Fct}=0.00974$ & 0.00035 & $7.02571 \mathrm{Va}$ & $89.04 \%$ \\
\hline & Among populations within groups & $\mathrm{FsC}=0.00774$ & 0.00058 & $1.05875 \mathrm{Vb}$ & $6.42 \%$ \\
\hline & Within populations & Fst $=0.0044$ & 0.00000 & $2.14570 \mathrm{Vc}$ & $4.54 \%$ \\
\hline & Total & & 0.00093 & 10.23016 & \\
\hline \multirow[t]{4}{*}{$\mathrm{COI}$} & Among groups & $\mathrm{Fct}=0.84075$ & 0.00000 & $18.02355 \mathrm{Va}$ & $84.17 \%$ \\
\hline & Among populations within groups & $F s C=0.33091$ & 0.00490 & $1.12977 \mathrm{Vb}$ & $5.17 \%$ \\
\hline & Within populations & Fst $=0.89343$ & 0.00000 & $2.28445 \mathrm{Vc}$ & $10.66 \%$ \\
\hline & Total & & 0.00490 & 21.43777 & \\
\hline \multirow[t]{4}{*}{ ITS1 } & Among groups & $\mathrm{Fct}=0.08049$ & 0.00000 & $0.06788 \mathrm{Va}$ & $8.11 \%$ \\
\hline & Among populations within groups & Fsc $=0.13758$ & 0.00000 & $0.10618 \mathrm{Vb}$ & $12.56 \%$ \\
\hline & Within populations & Fst $=0.20755$ & 0.00000 & $0.66475 \mathrm{Vb}$ & $79.33 \%$ \\
\hline & Total & & 0.00000 & 0.83881 & \\
\hline \multirow[t]{4}{*}{$E F-1 a+I T S 1$} & Among groups & $\mathrm{Fct}=0.06207$ & 0.00000 & $0.18647 \mathrm{Va}$ & $4.21 \%$ \\
\hline & Among populations within groups & $\mathrm{FsC}=0.11452$ & 0.00000 & $0.24571 \mathrm{Vb}$ & $10.33 \%$ \\
\hline & Within populations & Fst $=0.17504$ & 0.00000 & $0.30141 \mathrm{Vb}$ & $85.46 \%$ \\
\hline & Total & & 0.00000 & 0.73369 & \\
\hline
\end{tabular}


Table 3 Genetic diversity and neutrality tests calculated for populations

\begin{tabular}{lllllll}
\hline Population & NS & Nh & $H \pm S D$ & $\pi \pm S D$ & Tajima' D & Fu's Fs \\
\hline FX & 18 & 2 & $0.278 \pm 0.037$ & $0.00087 \pm 0.00033$ & 0.77973 & -1.691 \\
HC & 20 & 3 & $0.424 \pm 0.061$ & $0.00142 \pm 0.00016$ & 0.26627 & $-1.8622^{*}$ \\
HL & 20 & 3 & $0.298 \pm 0.018$ & $0.00017 \pm 0.00003$ & $-2.005^{*}$ \\
LF & 20 & 9 & $0.968 \pm 0.026$ & $0.00191 \pm 0.00023$ & -0.96593 & -10.779 \\
LL & 20 & 3 & $0.605 \pm 0.102$ & $0.00091 \pm 0.00025$ & -1.20798 & -1.352 \\
PL & 17 & 2 & $0.233 \pm 0.180$ & $0.00044 \pm 0.00017$ & 0.02107 & -0.742 \\
TB & 2 & 1 & - & - & -1.50776 & -1.744 \\
TC & 18 & 3 & $0.216 \pm 0.124$ & $0.00009 \pm 0.00006$ & -0.10574 & -0.022 \\
YA & 20 & 3 & $0.576 \pm 0.124$ & $0.00091 \pm 0.00028$ & -0.94371 & -1.744 \\
YH & 10 & 2 & $0.367 \pm 0.086$ & $0.00139 \pm 0.00037$ & & - \\
\hline
\end{tabular}

NS number of samples, $N h$ number of haplotypes, $H$ haplotype diversity, $\pi$ nucleotide diversity, SD standard deviation, ${ }^{*}$ Significant value

\section{Calling song structure comparison among populations}

Calling song patterns indicate that male S. yangi produce timbal and stridulatory sounds alternately. In the HL population, the calling duration of an entire song consisting of one timbal sound and one stridulatory sound is approximately $451.1 \pm 40.7 \mathrm{~ms}$ (mean $\pm \mathrm{SD}$; range $=$ 410.4-491.7 ms) $(N=23)$ (Fig. 5a, b). Each timbal sound is composed of $\sim 3-7$ echemes (Fig. 5a, b). The power spectrum shows two main parts (F1 and F2) in the frequency domain of each timbal sound (Fig. 5c, d): F1, possessing the maximum amplitude, is between $6.29 \sim 7.15 \mathrm{KHz}$ with a peak around $6.72 \mathrm{KHz}$; F2 is between $3.96 \sim 4.36 \mathrm{KHz}$ with a peak around $4.16 \mathrm{KHz}$. The spectral characteristics of the remaining populations are very similar (Fig. 6, Additional files 7 and 8: Figures S6 and S7), but significantly different from that of the HL population. Specifically, the duration of an integrated calling song comprising one timbal sound and stridulatory sound is approximately $324.1 \pm 36.1 \mathrm{~ms}$ (mean $\pm \mathrm{SD}$; range $=288.0-360.2 \mathrm{~ms})(N=21)$, and each timbal sound is made up of $\sim 2-4$ echemes (Fig. 6a, b). In contrast, the power spectrum in the remaining populations shows only one main part (F1) in the frequency domain of each timbal sound (Fig. 6c, d), which is between 6.61 8.09 $\mathrm{KHz}$ with a peak around $7.35 \mathrm{KHz}$.

The frequency domain of $\mathrm{F} 1$ of each timbal sound among the four representative populations (i.e., $\mathrm{HL}, \mathrm{HC}$, TC and PL) shows no significant difference $(P>0.05)$ (Fig. 7a), which is obviously higher than the exclusive dominant frequency F2 found in the HL population (Fig. 7a). The durations of both the timbal and stridulatory sounds of the HL population are remarkably different $(P<0.05)$ from those of the remaining populations (Fig. 7b). The HL population differs in calling song structure with respect to the dominant frequency of the timbal sound and the duration of both the timbal and stridulatory sounds $(P<0.05)$.

\section{Discussion}

Subpsaltria yangi is the only species of the subfamily Tettigadinae known from China [32]. This rare species was originally reported from the foothills of the Qinling Mountains [33]. It was thought to be extinct after intensive field investigations in recent decades [36]. After the

Table 4 Genetic differentiation among populations of S. yangi based on mitochondrial $(\mathrm{COI}+\mathrm{CO} / \mathrm{C}+\mathrm{Cytb}+\mathrm{A6A8}) \mathrm{genes}$

\begin{tabular}{|c|c|c|c|c|c|c|c|c|c|c|}
\hline Population & $F X$ & TB & TC & $\mathrm{HC}$ & YA & $\mathrm{LL}$ & LF & LFD & $\mathrm{PL}$ & $\mathrm{HL}$ \\
\hline \multicolumn{11}{|l|}{$\mathrm{FX}$} \\
\hline TB & 0.0101 & & & & & & & & & \\
\hline TC & 0.0101 & 0.0091 & & & & & & & & \\
\hline $\mathrm{HC}$ & 0.0121 & 0.0111 & 0.0124 & & & & & & & \\
\hline YA & 0.0166 & 0.0116 & 0.0090 & 0.0037 & & & & & & \\
\hline LL & 0.0141 & 0.0121 & 0.0084 & 0.0068 & 0.0018 & & & & & \\
\hline LF & 0.0181 & 0.0141 & 0.0099 & 0.0035 & 0.0235 & 0.0106 & & & & \\
\hline YH & 0.0155 & 0.0135 & 0.0096 & 0.0068 & 0.0158 & 0.0086 & 0.0019 & & & \\
\hline PL & $0.0578^{*}$ & 0.0408 & $0.0569^{*}$ & $0.0598^{*}$ & $0.0599^{*}$ & 0.0488 & 0.0485 & $0.0573^{*}$ & & \\
\hline $\mathrm{HL}$ & $0.0676^{*}$ & $0.0656^{*}$ & $0.0607^{*}$ & $0.0735^{*}$ & $0.0670^{*}$ & $0.0638^{*}$ & $0.0613^{*}$ & $0.0617^{*}$ & $0.0601^{*}$ & \\
\hline
\end{tabular}




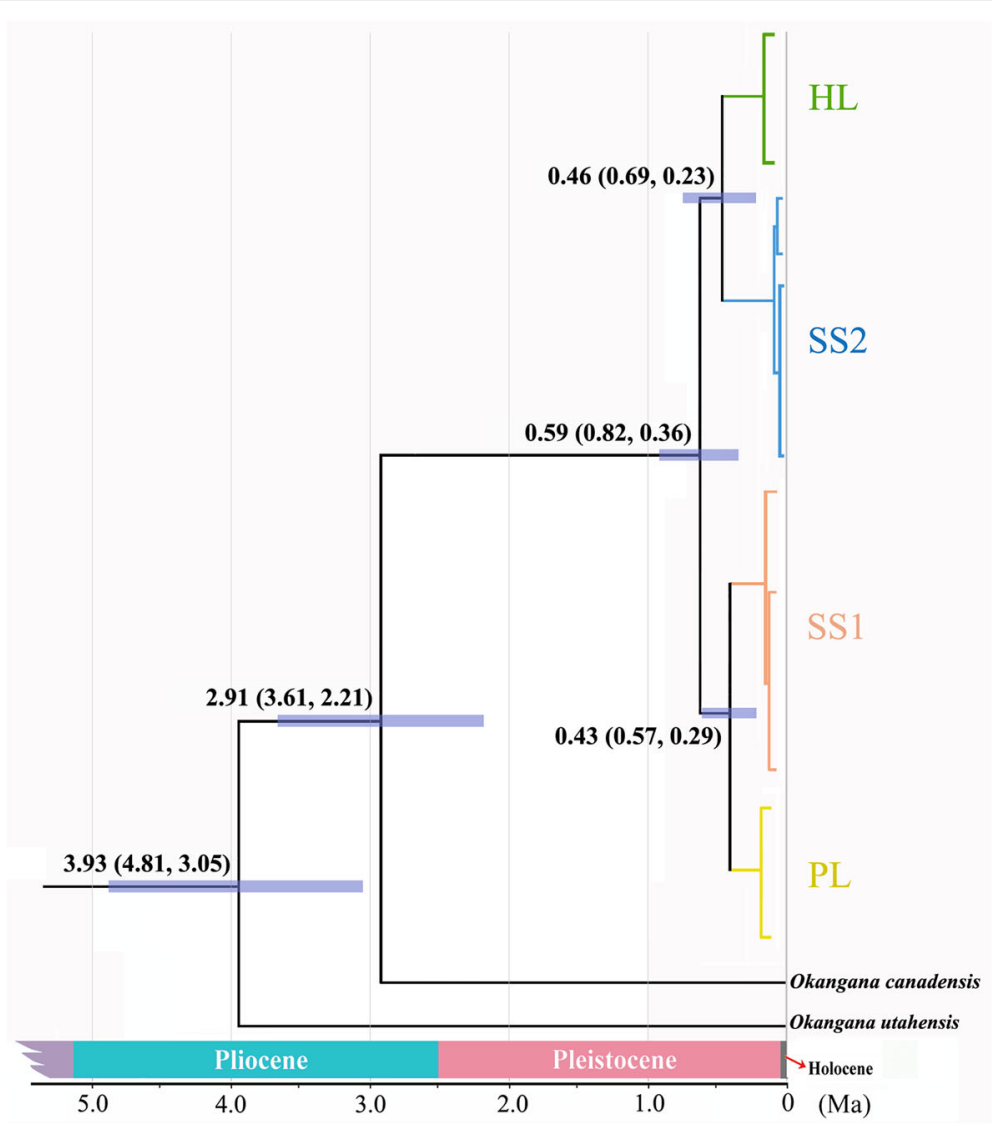

Fig. 4 Chronogram of S. yangi based on mtDNA data, using the conventional divergence rate of 3.54\% per million years. Estimates of divergence time are shown at nodes above branches. Divergence times at or below approximately $0.01 \mathrm{Ma}$ are not shown

discovery of a population of $S$. yangi from the Helan Mountains in June 2011, a few more populations were discovered using our special acoustic playback method [35]. Our distribution data for S. yangi suggest that this species is restricted to the Loess Plateau and adjacent areas of northwestern China. Previous studies show that S. yangi is similar to cicadas of the genus Paharia Distant in morphology and habitat (i.e., deserts and semi-deserts) [69-71]. Paharia cicadas are patchily distributed primarily in the Middle East [72]. Similarly, $S$. yangi occurs locally in patches of suitable habitat. The distribution patterns of Subpsaltria, Paharia and their relatives suggest that the evolution of this tribe has been closely tied to geographic range contraction resulting from historical climatic change [72].

Our study based on combined maternally inherited mitochondrial DNA and bi-parentally inherited nuclear genes provided a comprehensive framework to analyse the phylogeography and speciation of $S$. yangi. The population structure of $S$. yangi was revealed to comprise one large unit with low genetic diversity hierarchy but obvious differentiation was revealed between the HL population and other populations based on analyses of genetic distance, haplotype networks, and the calling song structure of males. The deserts and semi-deserts surrounding the Helan Mountains were previously shown to represent a major dispersal and climatic barrier [24]. Such barriers appear to have promoted divergence of the HL lineage from other lineages of S. yangi. Subsaltria yangi may, therefore, represent a new example of the early stage of speciation in insects. Cases such as this, where speciation occurs through geographic isolation and genetic differentiation of a peripheral population have been referred to as "budding speciation" [73].

Quaternary glaciations are often regarded as a major factor in forming the biodiversity of various extant species [12]. Our divergence-time estimates indicate that the geographical distribution and genealogical divergences of $S$. yangi are consistent with the scenario of glacial refugia and interglacial climate oscillation in northwestern China. Our estimates (Fig. 4) suggest that divergence between the HL population and other populations occurred in the Pleistocene $(0.15-2.5 \mathrm{Ma})$. In addition, our analysis shows that some divergence occured among populations in different habitats in spite of considerable gene flow [74], possibly due at least in 

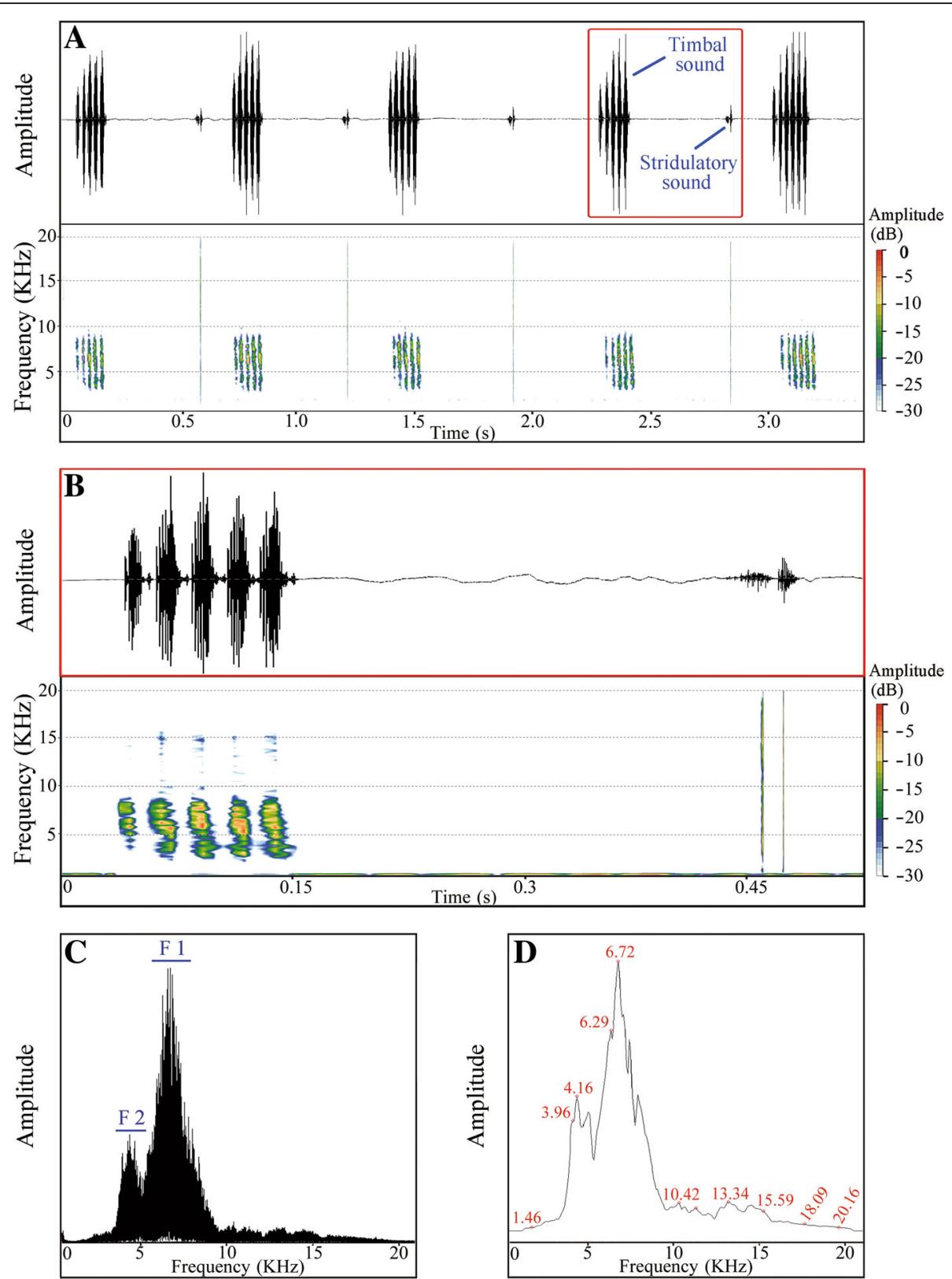

Fig. 5 Acoustic analyses of the male calling song structure of S. yangi from Helan Mountains, Ningxia (HL). a oscillogram and spectrogram of the timbal and stridulatory sounds shown alternately (i.e., upward and downward echemes). b detailed oscillogram and spectrogram of timbal and stridulatory sounds (marked by the red box in $\mathbf{a}$ ). $\mathbf{c}$, $\mathbf{d}$ power frequency spectrum with overlay of 174 spectra computed in the middle of the signal showing dominant frequencies marked by F1 and F2

part to habitat and host plant specialization. The HL population occurs at elevations of $1400-1600 \mathrm{~m}$ above the sea level, while other populations occur at elevations below $1000 \mathrm{~m}$ (Fig. 1). The Helan Mountains are located in the transition zone between the temperate and desert steppe where fauna and flora are complex in this monsoon boundary zone [20,75]. Furthermore, the HL population feeds on Ephedra lepidosperma (Ephedraceae), an endemic plant in the Helan Mountains, but other populations except the PL population occur in the Loess Plateau and adjacent areas and feed on Zizyphus jujuba Mill. var. spinosa (Bunge) Hu ex H. F. Chow. Hence, we hypothesise that ecological differences among habitats, coupled with the geographical isolation, might have reinforced genetic and behavioral divergence of the HL population.

Previous phylgeographic studies indicated that geographic barriers, including mountains, water bodies, deserts or inhospitable terrain, can drive speciation in geographically isolated populations [76, 77]. For example, genetic divergence in populations of many other 

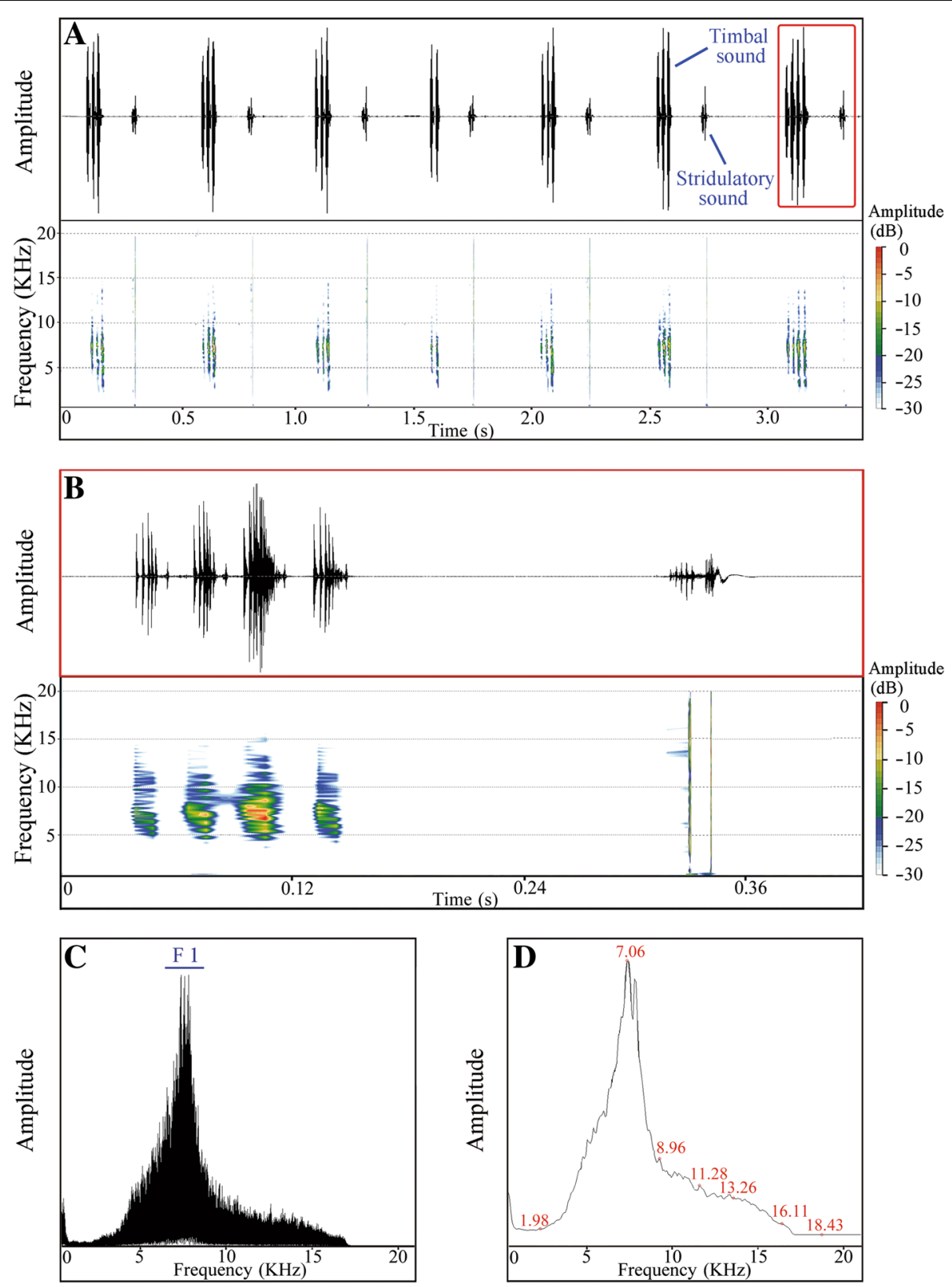

Fig. 6 Acoustic analyses of the male calling song structure of S. yangi from Hancheng (HC). a oscillogram and spectrogram of the timbal and stridulatory sounds shown alternately (i.e., upward and downward echemes). b detailed oscillogram and spectrogram of timbal and stridulatory sounds (marked by the red box in $\mathbf{a}$ ). $\mathbf{c}$, $\mathbf{d}$ power frequency spectrum with overlay of 174 spectra computed in the middle of the signal showing dominant frequencies marked by F1

insects, e.g., the beetle Carabus solieri [78], the butterfly Parnassius mnemosyne [79], the moth Apocheima cinerarius [8] and the ant Acromyrmex striatus [80], were revealed to be triggered by geographical barriers, and the contribution of geographic isolation is apparent in recent speciation events. Our study also found that geographical barriers (viz., the deserts and semi-deserts surrounding the Helan Mountains) played an important role in shaping the phylogeographical structure of S. yangi. Our phylogeny, genetic distances, BAPS and haplotype networks of $S$. yangi all indicate that a major genetic gap exists between the PL population and remaining individuals (Figs. 2 and 3; Table 4; Additional file 1: Table S4). Most likely, this was caused by the disruption of gene flow by the Liupan Mountains. During the late-Cenozoic, approximately 3.6 Ma, the Liupan Mountains rose to elevations of about $2600 \mathrm{~m}$ [81] which, together with the Qinling Mountains, obstructed the westward flow of the wet 

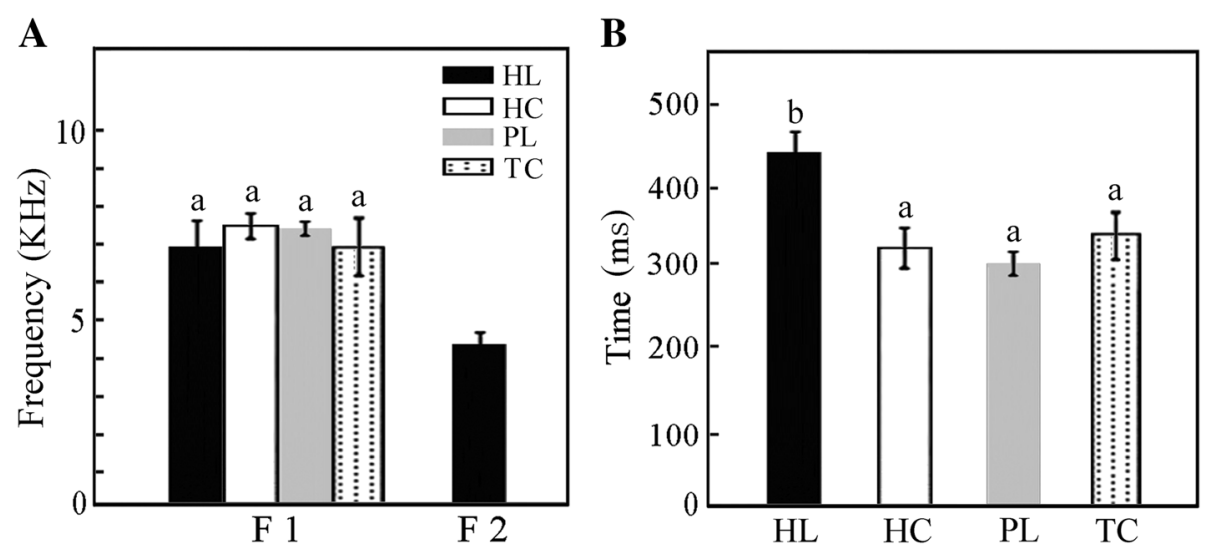

Fig. 7 Comparison of calling song structure of populations of S. yangi. a comparison of power frequency spectrum of F1 and F2 of four populations (mean \pm SD). $\mathbf{b}$ comparison of duration from a timbal sound to a stridulatory sound of four populations (data show mean \pm SD)

southeastern monsoon, and increased the aridity of western China [81, 82]. The climate of western China was dry and cold during the early late Pleistocene [83]. Accordingly, we presume that the independently evolved PL lineage is also associated with the natural barrier formed by the Liupan Mountains. During our field investigations, the PL population appears mostly to utilize Prunus mongolica Maxim as a host plant. This may represent another example of a host shift in S. yangi, similar to that already described for the HL population, and merits further study.

Ecological divergence and geography can both play important roles in speciation [84]. Previous studies have indicated that ecological factors may play an even more important role than geographical factors in shaping population structure [85]. Ecological specialization yielded suites of adaptive morphological traits and led to population divergence in animals like Timema walking-stick insects [86], Heliconius butterflies [87], Loxia crossbills [88], and Pundamilia cichlids [89]. In the case of S. yangi, although the deserts and semi-deserts surrounding the Helan Mountains represent a major dispersal and climatic barrier between the HL population and the remaining populations of $S$. yangi, we infer that the unique host, habitat and ecological environments of the HL population also contributed to divergence of this lineage yielding phenotypical differences from other populations. Our results also indicate that the PL population and the SS1 and SS2 groups represent different genetic lineages, but these populations do not show significant difference in the calling song structure (Figs. 4 and 7). This may also be consistent with a more recent divergence of the PL population compared to the HL population, which possibly indicates an even earlier stage of speciation than the HL population. The difference in calling song between HL and the other populations may have been a result from previous contact between HL and the other populations due to temporary merging of suitable habitats during a previous glacial cycle. Other studies (e.g., of frogs) have shown that when previously allopatric populations come into contact, they sometimes acquire additional precopulatory barriers to gene flow, such as different courtship songs [3]. Such behavioral divergence often does not occur as long as populations remain allopatric. This hypothesis for $S$. yangi needs to be tested by further analyses based on integrating phylogenetic and network approaches. Although the gene flow between the PL population and the SS1 as well as the SS2 groups may have been disrupted by the Liupan Mountains, the habitats occupied by these isolated populations are similar to each other. Previous studies demonstrated that, although time spent in isolation should be the primary factor in predicting phenotypic differentiation of ecologically similar allopatric populations [90], phenotypic differentiation in similar environments may take a long time [91]. The rate of phenotypic divergence among the PL population and the SS1 and SS2 populations may be lower due to lower selection pressure compared to that which occurred in the HL population.

Rivers have acted as substantial barriers to gene flow within some Chinese insects [92], plants [93, 94], and even birds $[95,96]$. Thus, we expected to find genetic divergence between populations of $S$. yangi occurring in Shaanxi and Shanxi provinces because they are located on the opposite sides of the Yellow River. However, samples distributed in Shaanxi and Shanxi showed no obviously genetic differentiation (Fig. 2). This is concordant with prior studies $[24,97]$ that showed the Yellow River did not act as a natural barrier to gene flow in some insects.

The cicada S. yangi has an unusual phonation mode among cicadas in that, besides the timbal organs of males, well-developed stridulatory organs are found in both sexes [35]. Cicadas are well known to have species-specific calling songs that enable individuals of sympatric species to distinguish among potential mates, and the calling song of male cicadas is routinely used as 
a taxonomic character [98]. Moreover, divergence in acoustic signals has a significant effect on speciation [17]. The underlying mechanisms driving divergence of acoustic traits and their consequences in S. yangi speciation remain poorly understood. Our study revealed that the calling song structure of the HL population distinctly differs in frequency domain and duration from that of the remaining populations (Fig. 7). The acoustical difference of the male calling song between the HL population and other populations, coupled with the results of molecular phylogenetic analyses (Figs. 2 and 3; Additional files 2 and 3: Figures S1 and S2), suggests that the isolated HL population has evolved into a distinct independent lineage. This suggests that premating isolation may evolve rapidly and result in rapid speciation in species with low levels of general genetic differentiation.

Finally, human activities are important factors that have shaped the current genetic structure of many species [99, 100]. Tainaka et al. [101] illustrated that frequent speciation or extinction may occur in communities undergoing rapid environmental change. Habitat fragmentation and destruction of host-plants by human activities, particularly agricultural practices, is a critical threat to populations of S. yangi [36]. Therefore, assessment of habitat conditions and conservation needs of this rare species should be conducted.

Estimated divergence time between $S$. yangi populations differed sharply depending on which conventional mtDNA divergence rate was used, i.e., 2.3\% versus 3.54\% per million years (Fig. 4, Additional file 6: Figure S5). When the $3.54 \%$ divergence rate was applied, the estimated age was congruent with the geological events that separated the main areas occupied by different populations of $S$. yangi and with the results of phylogeographic analysis based on combined mitochondrial gene data (Fig. 4). Nevertheless, the $2.3 \%$ standard clock appears to be satisfactory to estimate ages in many species based on only cytochrome oxidase I (COI) sequence data [63]. Preference for either of the two alternative conventional substitution rates (2.3 and $3.54 \%$ ) has tended to differ depending on the particular geologic events used in calibrating chronograms [64]. Further studies should be done to test the accuracy of divergence times in cicadas via applying alternative substitution rates and calibration methods.

Hierarchical analysis of molecular variance (AMOVA) [54] analyses population subdivision using F-statistics by measuring correlation between genetic variation which can be impacted by several evolutionary factors such as mutation rates or migration [102]. Unfortunately AMOVA requires an a priori definition of the hierarchical structuring of populations, which might introduce bias [54]. The AMOVA results may also differ between the nuclear and mitochondrial DNA [54, 103], as occurred in our study. The hypothesis of significant genetic structure among S. yangi haplogroups is well supported (Table 2), and 89.04 and $4.21 \%$ of the mtDNA and nuDNA genetic variation among groups were revealed, respectively. The analyses indicated that partitioning into the major haplogroups explains $89.04 \%$ of the overall mtDNA variability and corresponds to a highly significant fixation index $(p<0.0015$; Table 2). The AMOVA results for the COI gene show that mitochondrial genetic diversity is mostly explained by differences among groups, while for the nuclear gene ITS1, more genetic variation is found within populations (Table 2). The divergence between the four lineages of $S$. yangi indicates restricted gene flow and long-term isolation (Figs. 2 and 3), which should be caused by geographical barriers and the low dispersal ability of the species [104]. In contrast, AMOVA of the nuDNA data showed moderate, statistically significant nuclear allele divergence among the ten populations, but did not show statistically significant regional differences when we divided the populations into two regions. Nevertheless, our BAPS and network analyses identified two nuDNA groups (Fig. 3). We speculate that lower evolutionary rates may be the main cause of relative homogeneity in the nuclear genes $[105,106]$. The presence of unique haplotypes within each lineage indicates some degree of genetic differentiation of the nuclear genes has occurred between the two lineages and suggests that interbreeding among lineages is low, but further studies are needed to test this hypothesis.

Habitat fragmentation and desertification resulting from Quaternary glaciations and human activities are the most likely factors that yielded the observed genetic diversity and population differentiation in S. yangi. Ecological differences in habitats, coupled with the geographical isolation and diet shifts might also have contributed to the divergence of the HL and PL populations from other populations and may represent early stages of speciation. Further analyses on divergence time of this species based on more molecular loci are required to test this hypothesis. Our results improve the understanding of genetic differentiation, acoustic signal diversification and phylogeographic relationships of this rare species of conservation concern, and inform future studies on population divergence, speciation and phylogeography of other insects with a high degree of endemism in the Helan Mountains and adjacent areas.

\section{Additional files}

Additional file 1: Table S1. Primer names, sequences used in PCR reactions of genes sequenced. Table S2. List of grouping and haplotypes about populations with mtDNA and nuDNA genes. Table S3. Population clusters of S. hilpa found by BAPS. Table S4. Intraspecific and interspecific genetic distance of S. yangi and other related species based on (COI+COIl + Cytb + A6A8) gene. (DOCX $27 \mathrm{~kb})$ 
Additional file 2: Figure S1. Phylogram reconstructed based (EF-1a+ ITS1) genes. Bayesian posterior probabilities and ML bootstrap values are indicated near tree branches. (TIF $1020 \mathrm{~kb}$ )

Additional file 3: Figure S2. Phylogram reconstructed based (COI+ $\mathrm{CO} / 1+\mathrm{Cytb}+\mathrm{A} 6 \mathrm{~A} 8+$ EF-1a + ITS1) genes. Bayesian posterior probabilities and ML bootstrap values are indicated near tree branches. (TIF $1513 \mathrm{~kb}$ )

Additional file 4: Figure S3. Pairwise mismatch distribution of $\mathrm{HL}$ population. $X$ axis: Pairwise Differences. Y axis: Frequency. Obs means the observed distribution of pairwise difference. Exp means the expected equilibrium distributions. (TIF $1187 \mathrm{~kb}$ )

Additional file 5: Figure S4. Scatter plots of genetic distance vs. geographical distance for pairwise population comparisons (both analyses are calculated from 100,000 randomizations). (TIF 206 kb)

Additional file 6: Figure S5. The divergence time analysis of S. yangi based mtDNA gene, using the rate of $2.3 \%$ per million years. Estimates of divergence time are shown at nodes above branches. The divergence times occurred at approximately $0.01 \mathrm{Ma}$ and under $0.01 \mathrm{Ma}$ are not shown. (TIF $1010 \mathrm{~kb}$ )

Additional file 7: Figure S6. Acoustic analyses of the male calling song structure of S. yangi from Pingliang (PL). A, oscillogram and spectrogram of the timbal and stridulatory sounds were produced alternately (i.e., upward and downward echemes). B, detailed oscillogram and spectrogram of timbal and stridulatory sounds (marked by the red box in A). C, D, power frequency spectrum of the signal showing dominant frequencies marked by F1. (TIF $2804 \mathrm{~kb}$ )

Additional file 8: Figure S7. Acoustic analyses of the male calling song structure of S. yangi from Tongchuan (TC). A, oscillogram and spectrogram of the timbal and stridulatory sounds were produced alternately (i.e., upward and downward echemes). B, detailed oscillogram and spectrogram of timbal and stridulatory sounds (marked by the red box in A). C, D, power frequency spectrum of the signal showing dominant frequencies marked by F1. (TIF $3031 \mathrm{~kb}$ )

\section{Abbreviations}

A6A8: ATPase subunits; AMOVA: A three-level hierarchical analysis of molecular variance; BAPS: Bayesian analysis of population structure; BI: Bayesian analysis; BIC: Bayesian Information Criterion; BS: Bootstrap support value; COI: Cytochrome c oxidase subunit I; COIl: Cytochrome C oxidase subunit II; Cytb: Cytochrome b; DNA: Deoxyribonucleic acid; EF1a: Elongation factor-1 alpha gene; ESSs: Effective sample sizes; FFT: Fast Fourier Transform; HPD: Highest posterior density; ITS1: Internal transcribed spacer 1; K2P: Kimura two-parameter; MCMC: Markov chain Monte Carlo; ML: Maximum likelihood; mtDNA: Mitochondrial DNA; nuDNA: Nuclear DNA; PCR: Polymerase chain reaction; PP: Bayesian posterior probabilities: PSRF: Potential Scale Reduction Factor; QTP: Qinghai-Tibet Plateau; TBR: Tree bisection-reconnection

\section{Acknowledgements}

We would like to express our sincere thanks to Changqing Luo (Northwest A\&F University, Yangling, China) for his help with DNA extraction and field sampling.

\section{Funding}

This work was supported by the National Natural Science Foundation of China (Grant No. 31572302, 31772505). The authors declare there are no competing financial interests. The funders had no role in the study design, data collection and analysis, interpretation of data, or writing of the manuscript.

\section{Availability of data and materials}

The datasets supporting the conclusions of this article are included within the article. The datasets used and/or analysed during the current study are available from the corresponding author on reasonable request.

\section{Authors' contributions}

$\mathrm{CW}$ and $\mathrm{YL}$ conceived and designed the study. YL collected the specimen, carried out the molecular research and analysed the data. CHD interpreted part of the results. YL, CHD and CW drafted the manuscript. All authors revised and approved the manuscript.

\section{Ethics approval and consent to participate}

This study was carried out in full compliance with the laws of the People's Republic of China. No specific permits were required for our field investigation. The study species is not included in the 'List of Protected Animals in China'.

\section{Consent for publication}

Not applicable

\section{Competing interests}

The authors declare that they have no competing interests.

\section{Publisher's Note}

Springer Nature remains neutral with regard to jurisdictional claims in published maps and institutional affiliations.

\section{Author details}

${ }^{1}$ State Key Laboratory of Crop Stress Biology for Arid Areas, and Key Laboratory of Plant Protection Resources and Pest Management, Ministry of Education, College of Plant Protection, Northwest A\&F University, Yangling 712100, Shaanxi, China. ${ }^{2}$ Illinois Natural History Survey, Prairie Research Institute, University of Illinois, Champaign, IL 61820, USA.

Received: 5 February 2018 Accepted: 4 December 2018

Published online: 08 January 2019

\section{References}

1. Liu YX, et al. Morphological variation, genetic differentiation and phylogeography of the East Asia cicada Hyalessa maculaticollis (Hemiptera: Cicadidae). Syst Entomol. 2018:43:308-29.

2. Pyron RA, Burbrink FT. Hard and soft allopatry: physically and ecologically mediated modes of geographic speciation. J Biogeogr. 2010;37:2005-15.

3. Ye $\mathrm{S}$, et al. Phylogeographic analyses strongly suggest cryptic speciation in the giant spiny frog (Dicroglossidae: Paa spinosa) and interspecies hybridization in Paa. PLoS One. 2013;8:e70403.

4. Cheng $R$, et al. The influence of geological movements on the population differentiation of Biston panterinaria (Lepidoptera: Geometridae). J Biogeogr. 2016:43:691-702.

5. Cao M, et al. Effects of the Qinghai-Tibetan Plateau uplift and environmental changes on phylogeographic structure of the Daurian Partridge (Perdix dauuricae) in China. Mol Phylogenet Evol. 2012;65:823-830.

6. Qu Y, Lei F, Zhang R, Lu X. Comparative phylogeography of five avian species: implications for Pleistocene evolutionary history in the QinghaiTibetan plateau. Mol Eco. 2010;19:338-351.

7. $\mathrm{Hu}$ J, et al. Population genetic structure of the melon fly, Bactrocera cucurbitae (Diptera: Tephritidae), from China and Southeast Asia. Genetica. 2008;134:319-24.

8. Liu S, et al. Evolutionary history of Apocheima cinerarius (Lepidoptera: Geometridae), a female flightless moth in northern China. Zool Scr. 2016;45: 160-74.

9. Maekawa K, et al. Molecular phylogeny and geographic distribution of wood-feeding cockroaches in East Asian Islands. Mol Phylogenet Evol. 1999; 13:360-76.

10. Zhu GP, et al. Range wide molecular data and niche modeling revealed the Pleistocene history of a global invader (Halyomorpha halys). Sci Rep-UK. 2016;6:23192.

11. Hewitt GM. The genetic legacy of the quaternary ice ages. Nature. 2000;405:907-13.

12. Hewitt GM. Genetic consequences of climatic oscillations in the quaternary. Philos T R Soc B. 2004;359:183-95.

13. Morales-Barbero J, et al. Quaternary refugia are associated with higher speciation rates in mammalian faunas of the Western Palaearctic. Ecography. 2017:40:1-14

14. Jiang $Y$, et al. Plant biodiversity patterns on Helan Mountain, China. Acta Oecol. 2007;32:125-33.

15. Ye Z, et al. Phylogeography of a semiaquatic bug, Microvelia horvathi (Hemiptera: Veliidae): an evaluation of historical, geographical and ecological factors. Sci Rep-UK. 2016;6:21932.

16. Slabbekoorn HW. Singing in the wild: the ecology of birdsong. In: Marler P, Slabbekoorn HW, editors. Nature's Music: The Science of Birdsong. San Diego: Elsevier Academic Press; 2004. P. 78. 
17. Wilkins MR, Seddon N, Safran RJ. Evolutionary divergence in acoustic signals: causes and consequences. Trends Ecol Evol. 2012;30:1-11.

18. Liu XD, Li L, An ZS. Tibetan plateau uplift and drying in Eurasian interior and northern Africa. Quaternary Sci. 2001;21:114-22.

19. Shi YF, Li JJ, Li BY. Uplift and environmental changes of Qinghai-Tibetan Plateau in the Late Cenozoic. Guangzhou: Guangdong Science and Technology Press; 1998.

20. Zhao J, et al. The natural history of China. London: William Collins and Sons; 1990

21. Zhu X. Proper development and careful protection of land resources in the Loess Plateau. Sci Geogr Sin. 1984;4:97-105 (in Chinese).

22. Jiang $Y$, et al. Plant biodiversity patterns on Helan Mountain. China Acta Oecol. 2007;32:25-133.

23. Zhao Y. Rare and endangered plants in Inner Mongolia. Beijing: China Agricultural Science and Technology Press; 1992.

24. Gu L, et al. Quaternary climate and environmental changes have shaped genetic differentiation in Chinese pheasant endemic to the eastern margin of the Qinghai-Tibetan Plateau. Mol Phylogenet Evol. 2013;67:129-39.

25. Andreone F, Giacoma C. Breeding dynamics of Triturus carnifex at a pond in northwestern Italy (Amphibia, Urodela, Salamandridae). Holarct Ecol. 1989; 12:219-23.

26. Browne RA. Lakes as islands: biogeographic distribution, turnover rates, and species composition in the lakes of Central New York. J Biogeogr. 1981;8: 75-83.

27. Ellis EA, et al. Phylogeography of six codistributed New Zealand cicadas and their relationship to multiple biogeographical boundaries suggest a reevaluation of the Taupo Line. J Biogeogr. 2015;42:1761-75.

28. Marshall DC, et al. Limited, episodic diversification and contrasting phylogeography in a New Zealand cicada radiation. BMC Evol Biol. 2012;12:177.

29. Price BW, Barker NP, Villet MH. A watershed study on genetic diversity: phylogenetic analysis of the Platypeura plumose (Hemiptera: Cicadae) complex reveals catchment-specific lineages. Mol Phylogenet Evol. 2010;54: 617-26.

30. Marshall DC, Cooley JR. Reporoductive character displacement and speciation in periodical cicadas, with description of a new species, 13-year Magicicada neotredecim. Evolution. 2000;54:1313-25.

31. Pinto-Juma GA, Quartau JA, Bruford MW. Mitochondrial DNA variation and the evolutionary history of the Mediterranean species of Cicada $\mathrm{L}$. (Hemiptera, Cicadoidea). Zool J Linn Soc-Lond. 2009;155:266-88.

32. Chou I, et al. The Cicadidae of China (Homoptera: Cicadoidea). Hong Kong: Tianze Press; 1997

33. Chen KF. New genera and species of Chinese cicadas with synonymical and nomenclatorial notes. J New York Entomol S. 1943;51:19-52.

34. Marshell DC, et al. A molecular phylogeny of the cicadas (Hemiptera: Cicadidae) with a review of tribe and subfamily classification. Zootaxa. 2018; 4424:001-64.

35. Luo $C Q$, Wei $C$. Intraspecific sexual mimicry for finding females in a cicada: males produce 'female sounds' to gain reproductive benefit. Anim Behav. 2015;102:69-76.

36. Luo CQ, Wei C. Stridulatory sound-production and its function in females of the cicada Subpsaltria yangi. PLoS One. 2015;10:e0118667.

37. Hou ZH, et al. Sexual pair-formation in a cicada mediated by acoustic behaviour of females and positive phonotaxis of males. Sci Rep-UK. 2017:7:6453.

38. Thompson JD, et al. The Clustal $X$ windows interface: flexible strategies for multiple sequence alignment aided by quality analysis tools. Nucleic Acids Res. 1997;25:4876-82.

39. Hall TA. BioEdit: a user-friendly biological sequence alignment editor and analysis program for windows 95/98/NT. Nucl Acids Symp Se. 1999;41:95-8.

40. Lalitha S. Primer premier 5. Biotech Softw Int Rep Comput Softw J Scient. 2000;1:270-2

41. Castresana J. Selection of conserved blocks from multiple alignments for their use in phylogenetic analyses. Mol Biol Evol. 2000;17:540-52.

42. Xia X. DAMBE5: a comprehensive software package for data analysis in molecular biology and evolution. Mol Biol Evol. 2013;30:1720-8.

43. Tamura K, et al. MEGA6: molecular evolutionary genetics analysis version 6.0. Mol Biol Evol. 2013:30:2725-9.

44. Swofford DL. PAUP: phylogenetic analysis using parsimony (and other methods). Sunderland: Sinauer Associates; 2000.

45. Lanfear R, et al. PARTITIONFINDER: combined selection of partitioning schemes and substitution models for phylogenetic analyses. Mol Biol Evol. 2012;29:1695-701.
46. Ronquist F, Huelsenbeck JP. MrBayes3: Bayesian phylogenetic inference under mixed models. Bioinformatics. 2003;19:1572-4.

47. Silvestro D, Michalak I. RaxmIGUI: a graphical front-end for RAxML. Org Divers Evol. 2012;12:335-7.

48. Felsenstein J. Confidence limits on phylogenies: an approach using the bootstrap. Evolution. 1985:39:783-91.

49. Sueur J, et al. Molecular phylogeny of the genus Tibicina (Hemiptera, Cicadidae): rapid radiation and acoustic behaviour. Biol J Linn Soc. 2007;91: 611-26.

50. Rambaut A, Drummond AJ. Tracer Version1.5.0. 2009. Available at: http:// beast.bio.ed.ac.uk/software/tracer/. Accessed 15 Jan 2016.

51. Nei M. Molecular evolutionary genetics. New York \& Guildford: Columbia University Press; 1987.

52. Huson DH, Bryant D. Application of phylogenetic networks in evolutionary studies. Mol Biol Evol. 2006:23:254-67.

53. Bandelt HJ, Forster $P$, Röhl A. Median-joining networks for inferring intraspecific phylogenies. Mol Biol Evol. 1999;16:37-48.

54. Excoffier L, Smouse PE, Quattro JM. Analysis of molecular variance inferred from metric distances among DNA haplotypes: application to human mitochondria DNA restriction sites. Genetics. 1992;131:479-91.

55. Excoffier $L$, Lischer HE. Arlequin suite ver 3.5: a new series of programs to perform population genetics analyses under Linux and Windows. Mol Ecol Resour. 2010;10:564-7.

56. Corander J, Marttinen P. Bayesian identification of admixture events using multilocus molecular markers. Mol Ecol. 2006;15:2833-43.

57. Corander J, et al. Enhanced Bayesian modelling in BAPS software for learning genetic structures of populations. BMC Bioinformatics. 2008:9:539.

58. Slatkin M. A measure of population subdivision based on microsatellite allele frequencies. Genetics. 1995;1:457-62.

59. Bonnet E, Van D, Peer Y. ZT: a software tool for simple and partial mantel tests. J Stat Softw. 2002;7:1-12.

60. Drummond AJ, Rambaut A. BEAST: Bayesian evolutionary analysis by sampling trees. BMC Evol Biol. 2007;7:214.

61. Hill KBR, et al. Surviving glacial ages within the biotic gap: phylogeography of the New Zealand cicada Maoricicada campbelli. J Biogeogr. 2009;3:675-92.

62. Owen $\mathrm{CL}$, et al. How the Aridification of Australia structured the biogeography and influenced the diversification of a large lineage of Australian Cicadas. Syst Biol. 2016;66:1-21.

63. Brower AVZ. Rapid morphological radiation and convergence among races of the butterfly Heliconius erato inferred from patterns of mitochondrial DNA evolution. Proc Natl Acad Sci U S A. 1994;91:6491-5.

64. Papadopoulou A, Anastasiou I, Vogler AP. Revisiting the insect mitochondrial molecular clock: the mid-Aegean trench calibration. Mol Biol Evol. 2010;27:1659-72

65. Rambaut A. FigTree version 1.3.1. 2009. Available at: http://tree.bio.ed.ac.uk/ software/figtree/. Accessed 10 Jan 2016.

66. Sueur J, Aubin T, Simonis C. Seewave, a free modular tool for sound analysis and synthesis. Bioacoustics. 2008;18:213-26.

67. R Development Core Team. R: a language and environment for statistical computing. Vienna: R Foundation for Statistical Computing; 2011.

68. Puissant S, Sueur J. A hotspot for Mediterranean cicadas (Insecta: Hemiptera: Cicadidae): new genera, new species and new songs from southern Spain. Syst Biodivers. 2010;8:555-74

69. Duffels JP, Van der Laan PA. Catalogue of the Cicadoidea (Homoptera Auchenorhyncha) 1956-1980. Series Entomologica, Vol. 34. Dordrecht: Dr W Junk Publishers; 1985.

70. Metcalf ZP. General catalogue of the Homoptera, Fascicle VIII. Cicadoidea. Part 1. Cicadidae. Section 1. Tibiceninae. N C State Coll Contrib. 1963;1502:1-585

71. Sanborn AF. Catalogue of the Cicadoidea (Hemiptera: Auchenorrhyncha). With contributions to the bibliography by Martin H. Villet. San Diego: Elsevier Academic Press; 2013.

72. Wang $X$, Duffels JP, Wei $C$. Review of the cicada genus Paharia distant (Hemiptera, Cicadidae), with the description of a new species and its allied species. Eur J Taxon. 2017:349:1-14.

73. Cheng $\mathrm{R}$, et al. Complete mitochondrial genomes throw light on budding speciation in three Biston species (Lepidoptera, Geometridae). Zool Scr. 2017:46:73-84.

74. Warren $\mathrm{DL}$, et al. Mistaking geography for biology: inferring processes from species distributions. Trends Ecol Evol. 2014;29:572-80. 
75. Zhou TR, Ren SH. Physical geography of China: paleogeography. Beijing: Science Press; 1984.

76. Avise JC. Molecular population structure and the biogeographic history of a regional fauna: a case history with lessons for conservation biology. Oikos. 1992;63:62-76

77. Smith BT, et al. The drivers of tropical speciation. Nature. 2014:515:406-9.

78. Garnier $\mathrm{S}$, et al. Isolation by distance and sharp discontinuities in gene frequencies: implications for the phylogeography of an alpine insect species, Carabus solieri. Mol Ecol. 2004;13:1883-97.

79. Descimon H, Napolitano M. Enzyme polymorphism, wing pattern variability, and geographical isolation in an endangered butterfly species. Biol Conserv. 1993;66:117-23.

80. Cristiano MP, et al. Integrating Paleodistribution models and Phylogeography in the grass-cutting ant Acromyrmex striatus (Hymenoptera: Formicidae) in southern lowlands of South America. PLoS One. 2016;11:e0146734.

81. Song YG, et al. The late Cenozoic uplift of the Liupan Shan, China. Ser D Earth Sci. 2001;31:142-8.

82. Liu Y, et al. Effect of geological vicariance on mitochondrial DNA differentiation in common pheasant populations of the loess plateau and eastern China. Mol Phylogenet Evol. 2010;55:409-17.

83. Cao XS. The division of quaternary climate in Gansu Province. Arid Zone Res. 1996;13:28-40.

84. Nosil P. Ernst Mayr and the integration of geographic and ecological factors in speciation. Biol J Linn Soc. 2008;95:26-46.

85. Schacherer J, et al. Comprehensive polymorphism survey elucidates population structure of Saccharomyces cerevisiae. Nature. 2009;458:342-5.

86. Nosil P. Divergent host plant adaptation and reproductive isolation between ecotypes of Timema cristinae walking sticks. Am Nat. 2007;169: $151-62$.

87. Jiggins $C D$, et al. Reproductive isolation caused by colour pattern mimicry Nature. 2001;411:302-5.

88. Rundle HD, Nosil P. Ecological speciation. Ecol Lett. 2005;8:336-52.

89. Seehausen $\mathrm{O}$, et al. Evolution of colour patterns in East African cichlid fish. J Evol Biol. 1999;12:514-34.

90. Price T. Speciation in birds. Greenwood Village: Roberts and Company; 2008

91. Winger BM, Bates JM. The tempo of trait divergence in geographic isolation: avian speciation across the Marañon Valley of Peru. Evolution. 2015;69:772-87.

92. Zhu C, et al. Identifying paleoflood deposits archived in Zhongba site, the three gorges reservoir region of the Yangtze River, China. Chin Sci Bull. 2005;50:2493-504

93. Meng HH, Zhang ML. Phylogeography of Lagochilus ilicifolius (Lamiaceae) in relation to quaternary climatic oscillation and aridification in northern China. Biochem Syst Ecol. 2011;39:787-96.

94. Zhang T, Sun H. Phylogeographic structure of Terminalia franchetii (combretaceae) in Southwest China and its implications for drainage geological history. J Plant Res. 2011;124:63-73.

95. Li SH, et al. Sailing through the Late Pleistocene: unusual historica demography of an east Asian endemic, the Chinese Hwamei (Leucodioptron canorum canorum), during the last glacial period. Mol Ecol. 2009;18:622-33.

96. Song $\mathrm{G}$, et al. Phylogeography of the Alcippe morrisonia (Aves: Timaliidae): long population history beyond late Pleistocene glaciations. BMC Evol Biol. 2009:9:1-11.

97. Zhao Q, et al. Comparative population genetics and phylogeography of two lacertid lizards (Eremias argus and E. brenchleyi) from China. Mol Phylogenet Evol. 2011;58:478-91.

98. Quartau JA. Cigarras, esses insectos quase desconhecidos. Correio Natur. 1995;19:33-8.

99. Dasmahapatra KK, et al. The anatomy of a 'suture zone' in Amazonian butterflies: a coalescent-based test for vicariant geographic divergence and speciation. Mol Ecol. 2010;19:4283-301.

100. Ma C, et al. Mitochondrial genomes reveal the global phylogeography and dispersal routes of the migratory locust. Mol Ecol. 2012;21:4344-58.

101. Tainaka K, Itoh Y, Yoshimura J. A geographical model of high species diversity. Popul Ecol. 2006;48:113-9.

102. Excoffier L, Heckel G. Computer programs for population genetics data analysis: a survival guide. Nat Rev Genet. 2006;7:745-58.

103. Barbosa S, et al. Endemic species may have complex histories: withinrefugium phylogeography of an endangered Iberian vole. Mol Ecol. 2017;26: 951-67.
104. Avise JC, et al. Intraspecific phylogeography: the mitochondrial DNA bridge between population genetics and systematics. Annu Rev Ecol Evol S. 1987; 18:489-522.

105. Dong $L$, et al. Phylogeography of silver pheasant (Lophura nycthemera $L$.) across China: aggregate effects of refugia, introgression and riverine barriers. Mol Ecol. 2013;22:3376-90.

106. Ye Z, et al. Molecular data and ecological niche modelling reveal the Pleistocene history of a semi-aquatic bug (Microvelia douglasi douglasi) in East Asia. Mol Ecol. 2014;23:3080-96.
Ready to submit your research? Choose BMC and benefit from:

- fast, convenient online submission

- thorough peer review by experienced researchers in your field

- rapid publication on acceptance

- support for research data, including large and complex data types

- gold Open Access which fosters wider collaboration and increased citations

- maximum visibility for your research: over $100 \mathrm{M}$ website views per year

At BMC, research is always in progress.

Learn more biomedcentral.com/submissions 